\title{
Haemodynamic evaluation of diastolic abnormalities in hypertrophic cardiomyopathy
}

\author{
William Grossman, Walter Paulus and Beverly H. Lorell
}

\begin{abstract}
The Charles A. Dana Research Institute and the Harvard-Thorndike Laboratory of Beth Israel Hospital and the Department of Medicine (Cardiovascular Division), Beth Israel Hospital and Harvard Medical School, Boston, Massachusetts, USA.
\end{abstract}

\begin{abstract}
Summary: Haemodynamic studies suggest that an important abnormality in diastolic relaxation is characteristic of advanced hypertrophic cardiomyopathy. Current evidence supports the concept that cytosolic $\mathrm{Ca}^{++}$overload is the pathophysiological basis for this impaired relaxation, and may in turn represent impaired membrane $\mathrm{Ca}^{++}$pumping activity.
\end{abstract}

Diastolic abnormalities can alter the haemodynamic relationship between ventricular pressure and volume during chamber filling. The classic method of examining ventricular diastolic function is the diastolic pressure-volume plot (Figure 1). As seen in the left ventricular (LV) diastolic pressure-volume plot from the normal heart, LV diastolic pressure increases during ventricular filling, but the increase is not linearly proportional to volume. Changes in ventricular compliance or distensibility alter the relation between diastolic pressure and volume. As seen in Figure 1, increased LV diastolic pressure can result from either an increase in chamber volume $(A \rightarrow B)$, or an increase in chamber stiffness, with a higher diastolic pressure needed to fill the ventricle to the same chamber volume $(A \rightarrow C)$.

Altered diastolic distensibility of the left ventricle

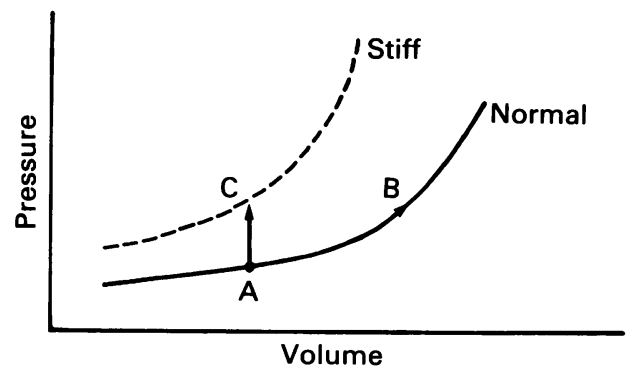

Figure 1 Diastolic pressure-volume relations for the left ventricle (LV) in the normal heart and in a heart with increased LV diastolic stiffness (decreased distensibility or compliance). See text for details.

Correspondence: W. Grossman, M.D., Cardiovascular Division, Harvard-Thorndike Laboratory, Beth Israel Hospital, 330 Brookline Avenue, Boston, Massachusetts 02215, USA. can result from a variety of processes. Two important determinants of LV diastolic chamber distensibility are listed in Table I. In hypertrophic cardiomyopathy (HCM), increased wall thickness contributes to altered LV diastolic distensibility, and accounts for some of the elevation in LV filling pressure seen in this condition. In addition, there may be some increase in collagen concentration and fibrosis in advanced cases, which would also increase passive diastolic chamber stiffness. Active elasticity of the LV chamber in diastole probably reflects diastolic cross-bridge cycling (Stern et al., 1983), and is present to a slight degree in normal cardiac muscle. However, substantial impairment of the relaxation process (including reversible and irreversible forms of contracture) may occur in a variety of settings, including hypoxia, ischaemia and calcium overload (Serizawa et al., 1981; Nayler et al., 1979; McLaurin et al., 1981; Lorell et al., 1981; Momomura et al., 1984; Carroll et al., 1983; Bourdillon et al., 1983; Henry et al., 1977; Bourdillon \& Poole-Wilson, 1981).

Several years ago, we had the opportunity to study a patient with severe hypertrophic cardiomyopathy (non-obstructive type) who had a history of orthopnoea and increasingly severe dyspnoea on exertion

Table I Two important determinants of LV chamber distensibility

1. Passive elasticity of chamber:

(a) Thickness of ventricular wall

(b) Composition of ventricular wall (i.e., muscle, fibrous tissue, amyloid, etc.)

2. Active elasticity of chamber (residual diastolic interaction between contractile elements):

(a) Incomplete relaxation, diastolic tone, contracture

(C) The Fellowship of Postgraduate Medicine, 1985 


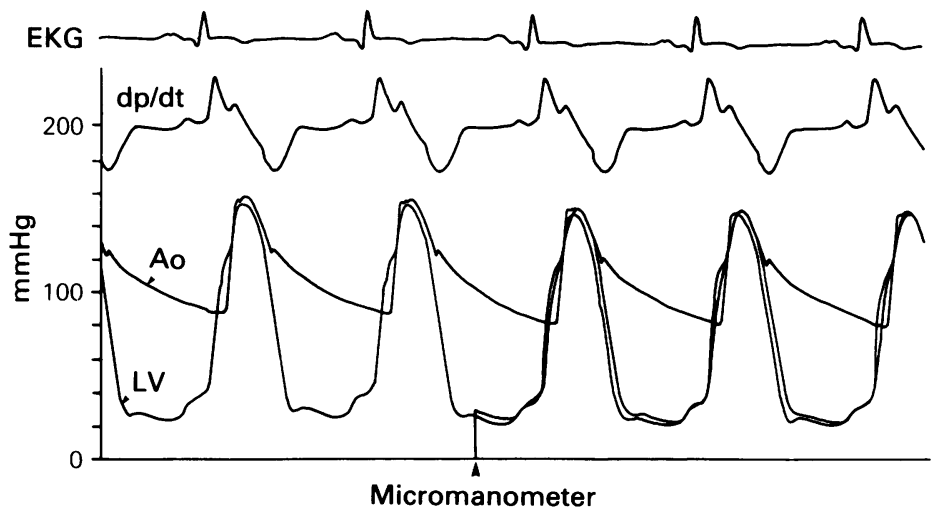

Figure 2 Abnormal left ventricular (LV) diastolic pressure waveform in a patient with advanced non-obstructive hypertrophic cardiomyopathy. Also shown are aortic (Ao) pressure and rate of rise of LV pressure, dp/dt. See text for details.

(Lorell et al., 1980). This 54 year old woman had an echocardiogram that showed marked asymmetric hypertrophy with an interventricular septum of $25 \mathrm{~mm}$ in thickness and a posterior LV wall thickness of $12 \mathrm{~mm}$. Cardiac catheterization showed marked increases in LV filling pressure, with pulmonary capillary wedge pressure of $32 \mathrm{~mm} \mathrm{Hg}$ and $\mathrm{LV}$ end-diastolic pressure $40 \mathrm{~mm} \mathrm{Hg}$, while cardiac index was decreased at 2.0 litres $/ \mathrm{min} / \mathrm{m}^{2}$. A remarkable finding was the abnormal appearance of the LV pressure waveform in diastole (Figure 2), which was consistently present despite repositioning of the LV catheter and measurement of pressure with a micromanometer tracing. We knew of the work from Germany (Kaltenbach et al., 1979; Hanrath et al., 1980) and from Bethesda (Rosing et al., 1981) supporting the value of the calcium antagonist verapamil in patients with hypertrophic cardiomyopathy, and we wondered whether the abnormal LV diastolic waveform in our patient represented slow and incomplete myocardial relaxation due to diastolic calcium overload. Accordingly, we administered nifedipine sublingually to this patient. The result was a substantial improvement in the $\mathrm{LV}$ diastolic pressure waveform with a reduction in filling pressure (Figure 3). This improvement occurred with no change in LV diastolic volume, so that the LV diastolic pressure-volume relationship shifted down ward, indicating increased distensibility. Subsequenf studies in a large number of patients with hypertrophic cardiomyopathy have supported the finding of beneficial effect of calcium-channel blockade on diastolic relaxation (Lorell et al., 1982; Paulus et al., 1983).

What is the mechanism for the impaired LV relaxation in patients with hypertrophic cardiomyopathy? Evidence is accumulating to suggest that intracellular calcium overload may be playing a crucial role in the pathophysiology of hypertrophic cardiomyopathy (Morgan \& Morgan, 1985; Lorell \& Barry, 1984). The
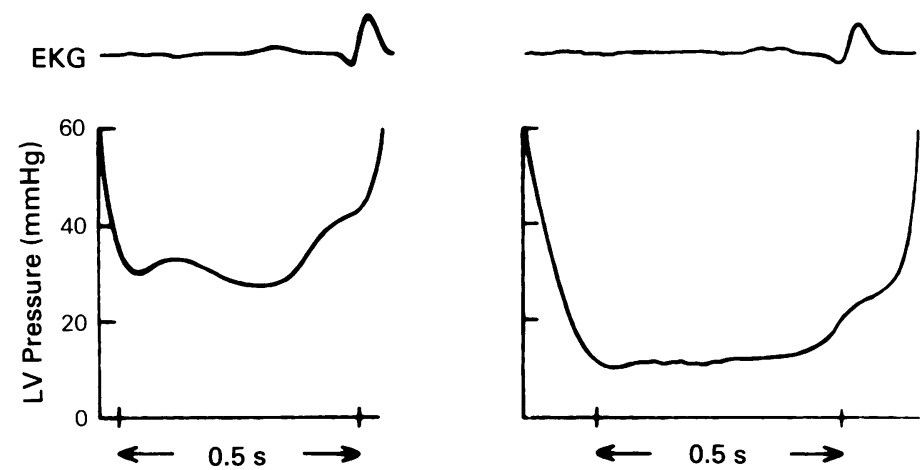

Figure 3 Improvement in abnormal diastolic relaxation following administration of a calcium blocking agent, nifedipine, to the patient illustrated in Figure 2. Reprinted from Lorrell et al. (1980) with permission. See text for details. 
disorder may be associated with a cellular defect in calcium metabolism, characterized perhaps by increased membrane permeability to calcium. Ordinarily, the myocardial cell defends its internal milieu against calcium overload by means of membrane pumps both on the external or sarcolemmal membrane, and the internal membrane of the sarcoplasmic reticulum (SR). The sarcolemmal calcium pumps are ATP-dependent and extrude $\mathrm{Ca}^{++}$from the cell against an enormous concentration gradient. Normally, the cytosolic $\mathrm{Ca}^{++}$concentration is $10^{-7} \mathrm{M}$ in diastole, whereas the $\mathrm{Ca}^{++}$concentration of interstitial fluid is approximately $10^{-3} \mathrm{M}$. The SR calcium pump also consumes ATP as it sequesters $\mathrm{Ca}^{++}$within the confines of $S R$ vesicles, again acting against a high concentration gradient. Membrane 'leakiness' and/or defective $\mathrm{Ca}^{++}$pump activity could lead to cytosolic $\mathrm{Ca}^{++}$overload. At first, this might result in increased inotropy, and it is noteworthy that in its early stages hypertrophic cardiomyopathy is characterized by abnormally high ventricular ejection fraction and $\mathrm{dp} /$ dt. Increased contractility would be expected to eventuate in hypertrophy (Grossman et al., 1983) which might be asymmetric if the cellular defect involved myocardial tissue only in one region. Once hypertrophy became advanced, subendocardial ischaemia

\section{References}

BOURDILLON, P.D.V.\& POOLE-WILSON, P.A. (1981). Effects of ischaemia and reperfusion on calcium exchange and mechanical function in isolated rabbit myocardium. Cardiovascular Research, 15, 121.

BOURDILLON, P.D., LORELL, B.H., MIRSKY, I., PAULUS, W.J., WYNNE, J. \& GROSSMAN, W. (1983). Increased regional myocardial stiffness of the left ventricle during pacing-induced angina in man. Circulation, 67, 316.

CARROLL, J.D., HESS, C.M., HIRZEL, H.O. \& KRAYENBUEHL, H.P. (1983). Exercise-induced ischemia: The influence of altered relaxation on early diastolic pressures. Circulation, 67, 521.

GROSSMAN, W. \& BARRY, W.H. (1980). Diastolic pressure volume relations in the diseased heart. Federation Proceedings, 39, 148.

GROSSMAN, W., CARABELLO, B.A., GUNTHER, S. \& FIFER, M.A. (1983). In Perspectives in Cardiovascular Research, Vol. 7, Myocardial Hypertrophy and Failure, Alpert, N.R. (ed). p. 1. Raven Press: New York.

HANRATH, P., MATHEY, D.G., KREMER, P., SONNTAG, F. \& BLEIFELD, W. (1980). Effect of verapamil on left ventricular isovolumic relaxation time and regional left ventricular filling in hypertrophic cardiomyopathy. American Journal of Cardiology, 45, 1258.

HENRY, P.D., SCHUCHLEIB, R., DAVIS, J., WEISS, E.S. \& SOBEL, B.E. (1977). Myocardial contracture and accumulation of mitochondrial calcium in ischemic rabbit heart. American Journal of Physiology, 233, H677.

KALTENBACH, M., HOPF, R., KOBER, G., BUSSMAN, D., KELBER. M. \& PETERSEN, Y. (1979). Treatment of would be expected to develop, as is common in a variety of conditions associated with marked LV hypertrophy (e.g. severe aortic stenosis). Ischaemia would further depress SR function with a resultant impairment in diastolic relaxation (Nayler et al., 1979; Lorell \& Barry, 1984; Grossman \& Barry, 1980). As diastolic relaxation became impaired, systolic function would also deteriorate (Lorell \& Barry, 1984) since there would be a smaller fraction of quiescent crossbridges available for systolic activation. This is only a hypothesis, and much work will need to be done to ascertain the fundamental defect in hypertrophic cardiomyopathy. However, Morgan and co-workers (1985) have obtained preliminary results on a study of intracellular calcium transients, measured with the photoluminescent protein aequorin, in cardiac muscle removed at surgery from patients with IHSS undergoing myomyectomy. These data suggest that the intracellular rise in free $\mathrm{Ca}^{++}$occurs rapidly and normally in myocytes from patients with hypertrophic cardiomyopathy, but the decline in free $\mathrm{Ca}^{++}$following activation is slow and prolonged, and correlates with a slow decline in muscle tension measured simultaneously. Whether this represents SR dysfunction or some other defect in these myocytes will require further study.

hypertrophic obstructive cardiomyopathy with verapamil. British Heart Journal, 42, 35.

LORELL, B.H. \& BARRY, W.H. (1984). Effects of verapamil on contraction and relaxation of cultured chick embryo ventricular cells during calcium overload. Journal of the American College of Cardiology, 3, 341.

LORELL, B.H., PAULUS, W., GROSSMAN, W., WYNNE, J., COHN, P.F. \& BRAUNWALD, E. (1980). Improved diastolic function and systolic performance in hypertrophic cardiomyopathy after nifedipine. New England Journal of Medicine, 303, 801.

LORELL, B.H., PAULUS, W.J., GROSSMAN, W., WYNNE, J. \& COHN, P.F. (1982). Modification of abnormal left ventricular diastolic properties by nifedipine in patients with hypertrophic cardiomyopathy. Circulation, 65, 499.

LORELL, B.H., TURI, Z. \& GROSSMAN, W. (1981). Modification of left ventricular response to pacing tachycardia by nifedipine in patients with hypertrophic cardiomyopathy. American Journal of Medicine, 71, 667.

MCLAURIN, L.P., ROLETT, E.L. \& GROSSMAN, W. (1981). Impaired left ventricular relaxation during pacing induced ischemia. American Journal of Cardiology, 32, 751.

MOMOMURA, S.I., BRADLEY, A.B. \& GROSSMAN, W. (1984). Left ventricular diastolic pressure segment length relations and end diastolic distensibility in dogs with coronary stenoses: an angina physiology model. Circulation $\mathbf{R e}$ search, 55, 203.

MORGAN, J.P. \& MORGAN, K.G. (1985). Calcium and cardiovascular function: intracellular calcium levels during contraction and relaxation of mammalian cardiac 
vascular smooth muscle as detected by aequorin. American Journal of Medicine, 77, 33.

NAYlER, W.G., POOLE-WILSON, P.A. \& WILliAMS, A. (1979). Hypoxia and calcium. Journal of Molecular Cellular Cardiology, 11, 683.

PAULUS, W.J., LORELL, B.H., CRAIG, W.E., WYNNE, J., MURGO, J.P. \& GROSSMAN, W. (1983). Comparison of the effects of nitroprusside and nifedipine on diastolic properties in patients with hypertrophic cardiomyopathy: altered left ventricular loading or improved muscle inactivation? Journal of the American College of Cardiology, 2, 879.

ROSING, D.R., CONDIT, J.R., MARON, B.J., KENT, K.M., LEON, M.B., RONOW, R.O., LIPSON, L.C. \& EPSTEIN, S.E. (1981). Verapamil therapy: a new approach to the phar- macologic treatment of hypertrophic cardiomyopathy. III. Effects of long-term administration. American Journal of Cardiology, 48, 545.

SERIZAWA, T., VOGEL, W.M., APSTEIN, C.S. \& GROSSMAN, W. (1981). Comparison of acute alterations in left ventricular relaxation and diastolic chamber stiffness induced by hypoxia and ischemia. Role of oxygen supply demand imbalance. Journal of Clinical Investigation, 68, 91.

STERN, M.D., KORT, A.A., RHATNAGAR, G.M. \& LAKATTA, E.G. (1983). Scattered light intensity fluctuations in diastolic rat cardiac muscle caused by spontaneous $\mathrm{Ca}^{++}$ dependent cellular mechanical oscillations. Journal of General Physiology, 82, 119. 